\title{
Xerostomia and Clinical Outcomes in Definitive Intensity Modulated Radiotherapy (IMRT) Versus Three-dimensional Conformal Radiotherapy (3D-CRT) for Head and Neck Squamous Cell Carcinoma: A Meta-analysis
}

\author{
FRANCESCA DE FELICE ${ }^{1}$, NICOLA PRANNO ${ }^{2}$, PIERO PAPI $^{2}$, ORLANDO BRUGNOLETTI $^{2}$, \\ VINCENZO TOMBOLINI ${ }^{1}$ and ANTONELLA POLIMENI ${ }^{2}$ \\ ${ }^{1}$ Department of Radiotherapy, Policlinico Umberto I, “Sapienza” University of Rome, Rome, Italy; \\ ${ }^{2}$ Department of Oral and Maxillofacial Sciences, Policlinico Umberto I, \\ "Sapienza” University of Rome, Rome, Italy
}

\begin{abstract}
Background/Aim: Intensity modulated radiotherapy (IMRT) has been compared with three-dimensional conformal radiotherapy (3D-CRT) in randomized clinical trials for head and neck squamous cell carcinoma (HNSCC). The aim of this meta-analysis was to evaluate the efficacy and toxicity of IMRT and $3 D-C R T$ and identify differences in grade $\geq 2$ xerostomia incidence and clinical outcomes. Materials and Methods: The preferred reporting items for systematic reviews and metaanalyses (PRISMA) statement was applied. Random-effects models were used. Primary endpoint was xerostomia of grade 2 or worse. Secondary endpoints were overall survival (OS) and loco-regional control (LRC). Results: Three randomized clinical trials representing 213 patients were identified. Global, grade $\geq 2$ acute xerostomia and late xerostomia at 1 and 2 years after treatment were reduced with the IMRT technique $(R R=0.71$, $95 \% C I=0.59-0.86, R R=0.45,95 \% C I=0.31-0.65$ and $R R=0.26$, $95 \% C I=0.15-0.46$, respectively). IMRT was not associated with significant $O S$ and LRC improvement compared with 3D-CRT, with OR of $0.70(95 \% C I=0.39-1.24 ; p=0.22)$ and 1.50 (95\%CI=0.75-2.98; $p=0.25)$. Conclusion: This meta-analysis explored the value of IMRT compared to $3 D-C R T$ and confirmed the superiority of IMRT over $3 D-C R T$ in terms of grade $\geq 2$ xerostomia rates, but not on clinical outcomes. Its positive impact on tumor control and survival remains to be proven.
\end{abstract}

This article is freely accessible online.

Correspondence to: Francesca De Felice, Department of Radiotherapy, Policlinico Umberto I, "Sapienza" University of Rome, Viale Regina Elena 326, Rome, Italy. Tel: +39 0649973411, Fax:+390649973411,e-mail: fradefelice@hotmail.it

Key Words: Radiotherapy, toxicity, xerostomia, head and neck cancer, treatment, survival, multidisciplinary team.
Radiation therapy (RT) with or without chemotherapy plays a central role in the treatment of head and neck squamous cell carcinoma (HNSCC), in both definitive and adjuvant setting (1). Intensity modulated RT (IMRT) technique is currently considered standard in RT treatment plans, mainly because of its ability to better limit the dose to adjacent organs at risk over three-dimensional conformal RT (3DCRT). However, due to the anatomical complexity of the head and neck region, the risk of RT-induced toxicities remains significant and xerostomia still represents a frequent RT-related complication in HNSCC patients (2). However, different studies have demonstrated that IMRT reduces moderate to severe xerostomia onset compared to 3D- CRT treatment (3-9). Whereas its real benefit on clinical outcomes, including overall survival (OS) and loco-regional control (LRC) rates, is still unclear, mostly because these studies were too small to allow any definite conclusion (39). Therefore, a pooled analysis of their results is necessary to power IMRT efficacy on clinical outcomes in HNSCC.

The aim of this meta-analysis was to perform a systematic review of the literature, to compare RT-induced xerostomia and clinical outcomes in HNSCC patients treated with IMRT or 3D-CRT and to provide valuable evidence for future research.

\section{Materials and Methods}

Data extraction and trials selection. The preferred reporting items for systematic reviews and meta-analyses (PRISMA) statement was followed to perform search strategy and selection processes (10). The meta-analysis included trials without any restrictions on publication date. The last search was carried out on May 2019. Systematic literature electronic search was conducted in Pubmed, Embase and Cochrane central register of controlled trials databases, using the following research criteria: "Head and Neck Neoplasms/radiotherapy"(Mesh) AND ("xerostomia" (MeSH Terms) OR "xerostomia"(All Fields)). The 
search strategy was linked with the Cochrane highly sensitive search strategy for identifying randomized trials in Pubmed (11). To be eligible, trials needed to compare IMRT and 3D-CRT in definitive HNSCC treatment. Randomized clinical trials, written in English, were included and reference lists of previously published reviews and meta-analysis were explored. Narrative or systematic review articles, retrospective studies, case series, case reports, commentaries, letters to editors and studies involving animals or in vitro models were not included. Meeting abstracts were not considered because of the insufficient data provided by the authors.

Two independent reviewers (NP and PP) selected the identified studies based on the title and abstract. If the topic of the study could not be ascertained from its title or abstract, the full-text version was retrieved for evaluation. Disagreement was resolved by a third party (FDF).

Trials were eligible if participants were newly diagnosed, with histologically proven squamous cell carcinoma at study entry. In closer evaluation of potentially eligible articles, when two articles appeared to report results with overlapping data, only the data representing the most recent publication were included in the metaanalysis. Extracted data were recorded into standardized database according to the following parameters: first author's surname, year of publication, sample size of IMRT group and 3D-CRT group, tumor and treatment details, duration of follow-up, xerostomia rates and clinical outcomes.

Focus question. This study attempted to address the following question: does the use of IMRT compared to 3D-CRT reduce the risk of acute and late xerostomia and improve LRC and OS in HNSCC patients?

Outcomes. The intent of the analysis was to evaluate the proportion of patients with grade $\geq 2$ acute and late xerostomia. Late xerostomia was assessed at 12 months and 24 months after treatment. We also planned to analyze OS and LRC. Xerostomia was graded using the radiation therapy oncology group and the European organization for research and treatment of cancer (RTOG/EORTC) +/- the late effects of normal tissues subjective-objective management analytic (LENT SOMA) (12). The definition of both OS and LRC was similar across trials. OS and LRC were defined as time from the date of randomization to the defined event using Kaplan-Meier method. The number of events (side effect, death and recurrence), when available, were derived from each study. At least one of these three outcomes should have been assessed and reported in the trial to be included in the present analysis.

Statistical analysis. The grading of recommendations assessment, development and evaluation (GRADE) system was used to rate quality of evidence and grade the strength of recommendations for all included studies (13). Statistical analysis was performed using Review Manager 5.0 (14). The pooled odds ratio (OR) and risk ratio (RR) were calculated using a fixed- or random-effects model. Forest plots were used for graphical representation of each study and pooled analysis. The size of each box represents the weight that the corresponding study exerts in the meta-analysis; confidence intervals (CIs) for each study are displayed as a horizontal line through the box. The pooled OR and RR are symbolized by a solid diamond at the bottom of the forest plot, and the width of the square represents the $95 \% \mathrm{CI}$ of the OR and RR. OR, RR and 95\%CI, for each study were extracted or calculated, based on the published

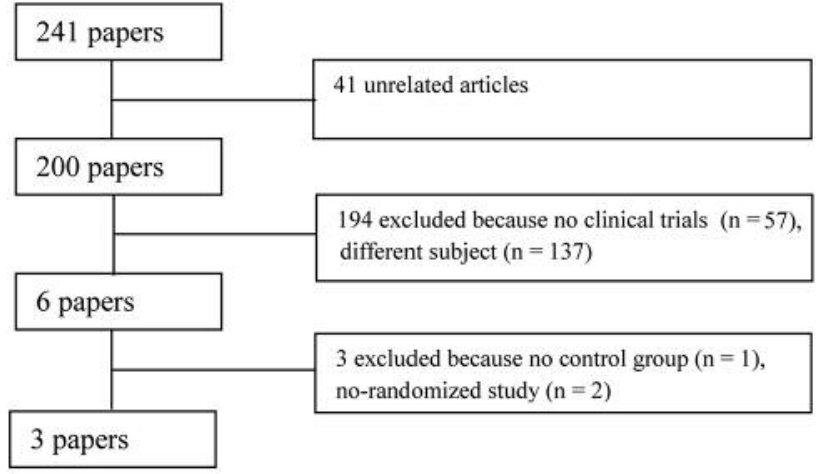

Figure 1. Flow chart.

studies, according to the methods described by Tierney et al. in 2007 (15). A significant two-way $p$-value for comparison was defined as $p<0.05$. Statistical heterogeneity among studies was examined using both the Cochrane Q statistic (significant at $p<0.1$ ) and the $\mathrm{I}^{2}$ value (significant heterogeneity if $>50 \%$ ) (16).

\section{Results}

Studies' characteristics. Flowchart of the retrieved studies and their main characteristics are presented in Figure 1 and Table I. Overall, 3 randomized clinical trials, representing 213 patients were included in the final analysis $(5,8-9)$. Studies included only patients with oral cavity $(n=3)$, oropharynx $(n=137)$, hypopharynx $(n=0)$ and larynx $(n=23)$ cancer, except T1N0 glottic larynx. Patients were randomly assigned to 3D-CRT $(n=104)$ versus IMRT $(n=109)$. Except for 23 adjuvant treatments [in Nutting et al. trial (5)], all patients received definitive chemoradiotherapy.

Xerostomia. Grade $\geq 2$ toxicity analysis mainly demonstrated a benefit in favor of IMRT. The risk of acute $(\mathrm{RR}=0.71$, $95 \% \mathrm{CI}=0.59-0.86), 1$-year $(\mathrm{RR}=0.45,95 \% \mathrm{CI}=0.31-0.65)$ and 2-year $\quad(\mathrm{RR}=0.26,95 \% \mathrm{CI}=0.15-0.46)$ xerostomia was consistently and significantly reduced with the IMRT technique. Details are presented in Figure 2. Quality of evidence and strength of recommendation is summarized in Table II.

Survival outcomes. Compared to 3D-CRT, IMRT was not associated with a significant reduction in the risk of death $(\mathrm{OR}=0.70,95 \% \mathrm{CI}=0.39-1.24 ; p=0.22)$. There was no significant difference in LRC between IMRT and 3D-RT $(\mathrm{OR}=1.50,95 \% \mathrm{CI}=0.75-2.98 ; p=0.25)$. The $\chi^{2}$ tests for heterogeneity of both comparisons showed no significant heterogeneity. Details are shown in Figure 3. The quality of evidence and strength of recommendations for survival outcomes are presented in Table II. 
a

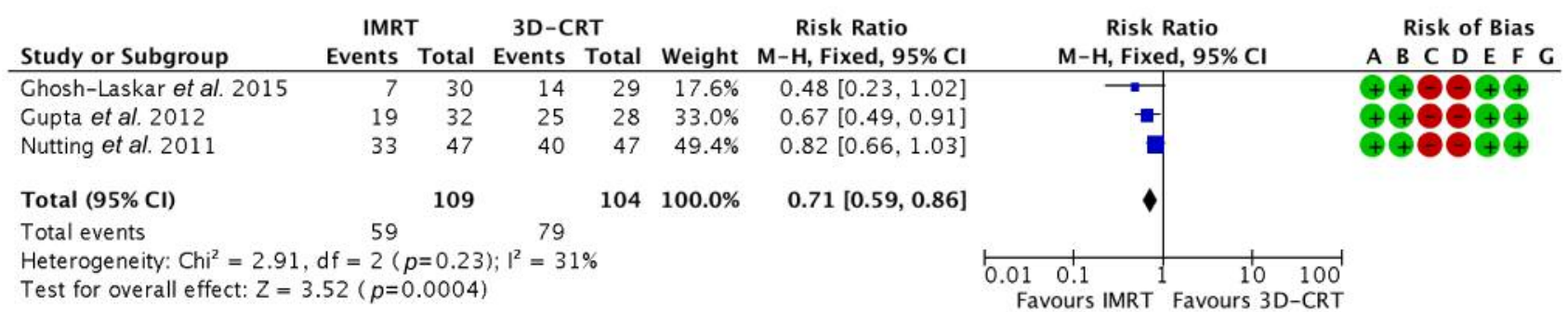

b

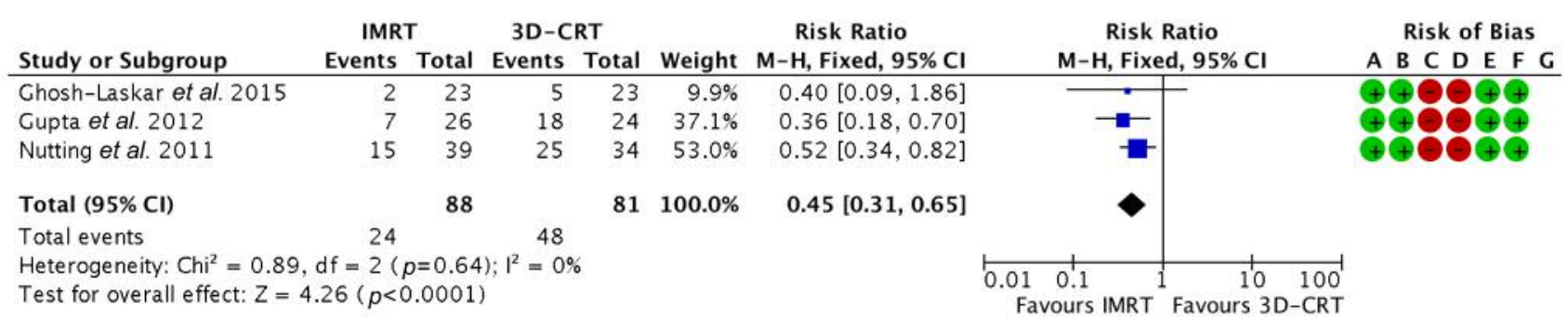

c

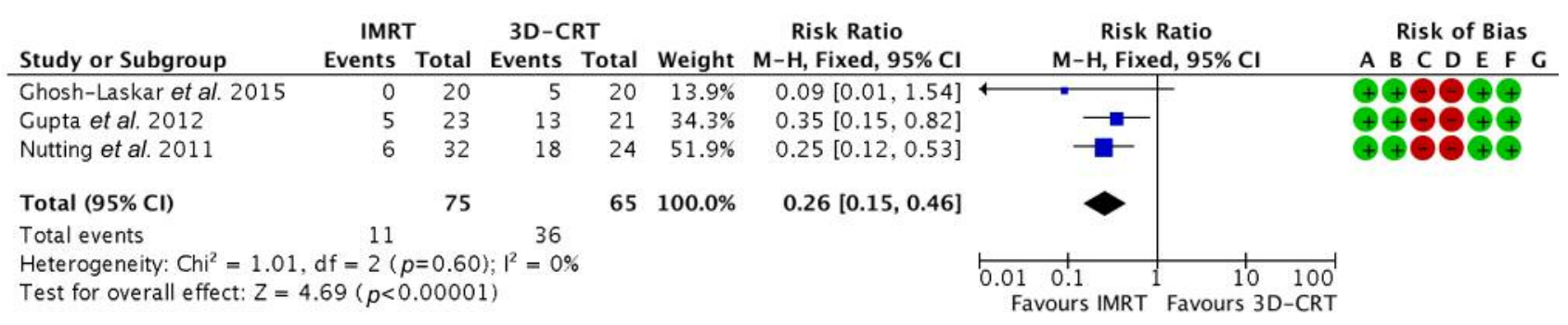

Risk of bias legend

(A) Random sequence generation (selection bias)

(B) Allocation concealment (selection bias)

(C) Blinding of participants and personnel (performance bias)

(D) Blinding of outcome assessment (detection bias)

(E) Incomplete outcome data (attrition bias)

(F) Selective reporting (reporting bias)

(G) Other bias

Figure 2. Forest plot of acute (a), 1-year (b) and 2-year (c) xerostomia profile.

\section{Discussion}

Our results indicated that for HNSCC patients IMRT was superior to 3D-CRT in the xerostomia-related toxicity profile, while showed no benefit on OS and LRC rates. Data were statistically homogeneous and results were robust. IMRT was associated with decreased grade $\geq 2$ acute xerostomia and there was a significant difference in late xerostomia between 3D-CRT and IMRT at 1-year and 2years after treatment. Although the direct comparison between IMRT and 3D-CRT did not show the superiority of IMRT regarding clinical outcomes, there was a slight increase in local recurrence events in the IMRT group. This higher proportion of events was small but it may have important implications for RT treatment planning. In fact, despite significant progress in the RT technique, the risk of loco-regional failure remains a challenge, mainly related to radio-resistant tumor areas and/or geographic miss (17). In order to improve accuracy in target definition to guarantee good outcomes in terms both of cure and toxicity, fusion of 
Table I. Details of the included studies.

\begin{tabular}{|c|c|c|c|c|c|c|c|c|}
\hline \multirow[b]{2}{*}{ Author } & \multirow[b]{2}{*}{ ID_study } & \multirow[b]{2}{*}{ Population } & \multicolumn{3}{|c|}{ Patients } & \multirow[b]{2}{*}{ Median FU } & \multirow[b]{2}{*}{ Primary end point } & \multirow[b]{2}{*}{ Comments } \\
\hline & & & Total & IMRT & 3D-CRT & & & \\
\hline $\begin{array}{l}\text { Ghoshlaskar_2015 } \\
\text { (8) }\end{array}$ & NCT652613 & $\begin{array}{l}\text { T1-3 N0-2b } \\
\text { oral cavity, oropharynx, } \\
\text { larynx* or hypopharynx }\end{array}$ & 59 & 29 & 30 & 70 months & $\begin{array}{l}\text { Xerostomia } \\
\quad \mathrm{G} \geq 2\end{array}$ & $\begin{array}{c}\text { Toxicity was graded } \\
\text { using the RTOG } \\
\text { scoring system }\end{array}$ \\
\hline Gupta_2012 (9) & $\begin{array}{l}\text { CTRI/2008/ } \\
\text { 091/000045 }\end{array}$ & $\begin{array}{l}\text { T1-T3 N0-2b } \\
\text { oropharynx, larynx* } \\
\text { or hypopharynx }\end{array}$ & 60 & 28 & 32 & 40 months & $\begin{array}{l}\text { Xerostomia } \\
\quad \mathrm{G} \geq 2\end{array}$ & $\begin{array}{l}\text { Toxicity was } \\
\text { assessed based } \\
\text { on the RTOG } \\
\text { scoring system }\end{array}$ \\
\hline Nutting_2011 (5) & ISRCTN48243537 & $\begin{array}{c}\text { T1-4 N0-3 } \\
\text { oropharynx } \\
\text { or hypopharynx }\end{array}$ & 94 & 47 & 47 & 44 months & $\begin{array}{c}\text { Xerostomia } \\
\quad \mathrm{G} \geq 2\end{array}$ & $\begin{array}{l}\text { Acute side-effects } \\
\text { were graded with } \\
\text { NCICT. Late } \\
\text { RT side-effects were } \\
\text { assessed with LENT } \\
\text { SOMA and RTOG } \\
\text { scoring systems }\end{array}$ \\
\hline
\end{tabular}

*Except T1N0 glottic larynx. ID: Identifier; IMRT: intensity modulated radiotherapy; 3D-CRT: three dimensional conformal radiotherapy; FU: follow-up; NCT: number clinical trial; G: grade; RTOG: Radiation Therapy Oncology Group; CTRI: Clinical Trials Registry-India; ISRCTN: International Standard Randomized Controlled Trial; NCICT: National Cancer Institute Common Toxicity Criteria; LENT SOMA: Late Effects of Normal Tissues Subjective-Objective Management Analytic.

functional imaging examination at the contouring stage should be standardized (18).

To minimize indirectness, we restricted the analysis only to those trials that excluded nasopharynx cancer population. This can be explained clinically by nasopharyngeal cancer specific etiology, histology and natural history. It is not surprising that results on survival were not completely in agreement with the previous meta-analysis (4). Both LRC $(\mathrm{HR}=0.76,95 \% \mathrm{CI}=0.57-1.01)$ and $\mathrm{OS} \quad(\mathrm{HR}=0.70$, $95 \% \mathrm{CI}=0.57-0.88$ ) benefits of IMRT compared to non-IMRT techniques were clearly driven by the nasopharyngeal series. Authors performed subgroup analysis stratified by primary tumor site and these results were comparable to our findings. There was no significant difference in LRC $(\mathrm{HR}=1.06$, $95 \% \mathrm{CI}=0.71-1.58)$ and $\mathrm{OS}(\mathrm{HR}=0.85,95 \% \mathrm{CI}=0.63-1.15$; $p=0.29$ ) between IMRT and non-IMRT (4). Also, xerostomia outcomes were not very different compared to our results, reporting a consistent IMRT benefit in salivary function over conventional techniques (4).

Despite the lower incidence, xerostomia remains a major clinical problem in the IMRT era and parotid-sparing is the recommended method to its prevention (5). But, the importance of the other salivary glands, including both mayor submandibular and sublingual - and minor - upper/lower lip, buccal mucosa, postero-lateral hard palate, Von Ebner and Weber Blandin Nuhn - glands in quantity, quality and consistency of saliva production should be highlighted (19). In contrast to parotid glands, data on anatomic and dosimetric changes of the other salivary glands are scarce. In general, the mucinous component is more radio-resistant than serous cells and thus a higher threshold dose is expected for submandibular and minor salivary glands than parotid glands. Reducing submandibular glands mean dose to 39 Gy resulted in gradually improved flow rates and patient-reported dry mouth symptoms, but it was associated to modest rise in the mean doses to surrounding structures, including parotid glands and swallowing structures (20). Probably, to maximize therapeutic gain, radiation dose should be optimized not only to parotids but to all salivary glands. Both major and minor salivary glands-sparing should be the key to preserve salivary function but this benefit could be achieved at the cost of disease control, resulting in increased risk of marginal failures. The best balance between tumor target coverage and salivary glandssparing approach requires further clinical investigation before any definitive conclusion can be reached. This meta-analysis did not attempt to evaluate the other potential xerostomiarelated complications, such as late radiation-associated dysphagia (RAD) and osteoradionecrosis (ORN). Data were not suitable for a cumulative analysis. Obviously late RAD and ORN are also influenced by the direct irradiation of the swallowing apparatus and segments of mandible, respectively. Due to its ballistic characteristics, IMRT exposed large volume of these normal structures to higher doses than previous less conformal treatment, resulting in the highest risk of their damage (21). To reduce this detrimental RT effect, over the years, specific dose-volume parameters have been proposed in addition to the standard maximum dose constraints (22-23). But, at present, these specific constraints have been definitively 


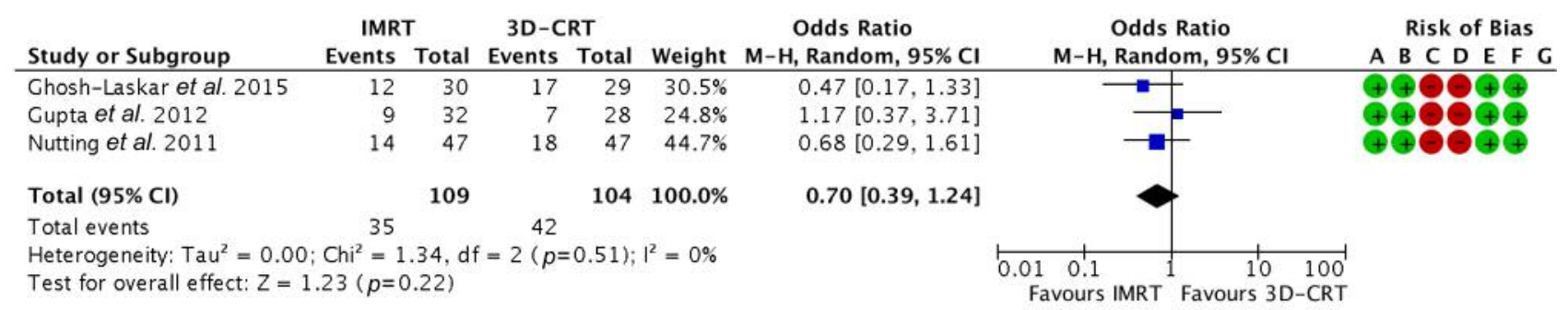

b

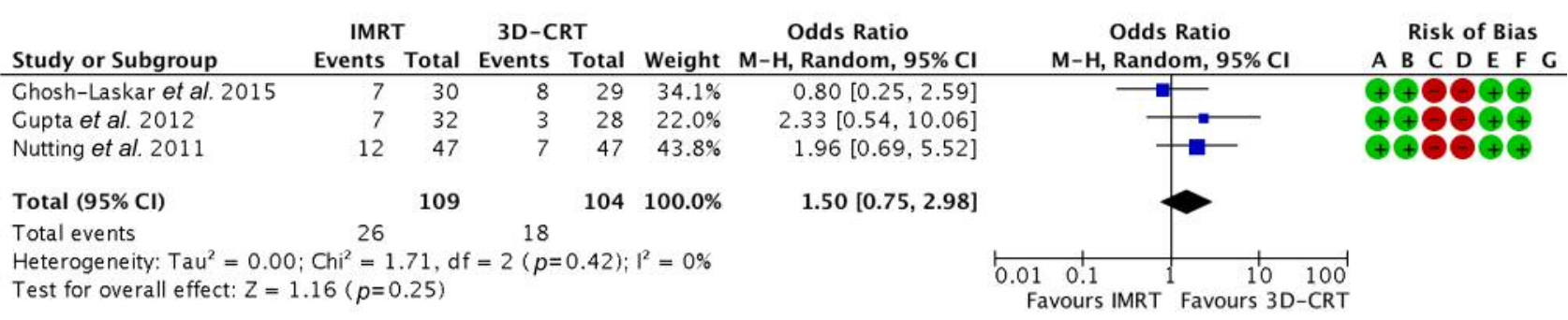

Risk of bias legend

(A) Random sequence generation (selection bias)

(B) Allocation concealment (selection bias)

(C) Blinding of participants and personnel (performance bias)

(D) Blinding of outcome assessment (detection bias)

(E) Incomplete outcome data (attrition bias)

(F) Selective reporting (reporting bias)

(G) Other bias

Figure 3. Forest plot of overall survival (a) and loco-regional control (b).

introduced in daily clinical practice. Optimizing future multimodal treatment for HNSCC requires collection of detailed toxicity data, both clinician-reported and patientreported outcomes (PROs) (24). A plausible discordance between clinician and patient reporting of toxicity should be considered. For instance, patients in disease remission may have accepted moderate xerostomia, adjusting their expectation accordingly; whereas in other cases the same clinician-reported moderate RT toxicity may drastically impact patient quality of life. PROs inclusion in the rigorous toxicity reporting methods should be useful to provide additional information in decision making process.

In general, this meta-analysis provided additional contribution to published literature data, showing the superiority of IMRT over 3D-CRT in HNSCC patients management. Our main aim was to achieve the highest quality of research. The current meta-analysis was not a literature abstract-based meta-analysis. Conference proceedings were not considered, due to the lack of statistical quality details and $<$ given the variable evidence of concordance between conference abstracts and their subsequent full-text publications $>>$, as advised by the agency for healthcare research and quality (AHRQ) (25). All included studies were randomized clinical trials and addressed the same primary end-point and similar methods were used to evaluate xerostomia. The major limitation of the analysis was the relative limited number of trials. But trials' short time accrual period - ranged from 2003 to 2008 - may add homogeneity to results, even though the included trials did not record human papillomavirus (HPV) status. At present HPV evaluation is paramount in HNSCC risk stratification (26). Its positive status discriminates excellent prognosis disease from worst outcome in HPV-negative tumors. Future studies specifically designed and powered to test the benefit of IMRT over 3D-CRT based on HPV stratification and salivary glands-sparing RT approach would provide more 
Table II. Quality of evidence and strength of recommendation: Summary of findings. Intensity modulated radiotherapy (IMRT) compared to threedimensional conformal radiotherapy (3D-CRT) in head and neck squamous cell carcinoma.

\begin{tabular}{|c|c|c|c|c|c|c|}
\hline \multirow[t]{2}{*}{ Outcomes } & \multicolumn{2}{|c|}{$\begin{array}{l}\text { Anticipated absolute effects* } \\
\qquad(95 \% \mathrm{CI})\end{array}$} & \multirow[t]{2}{*}{$\begin{array}{l}\text { Relative effect } \\
\quad(95 \% \mathrm{CI})\end{array}$} & \multirow[t]{2}{*}{$\begin{array}{c}\text { No. of participants } \\
\text { (studies) }\end{array}$} & \multirow[t]{2}{*}{$\begin{array}{l}\text { Certainty of the evidence } \\
\text { (GRADE) }\end{array}$} & \multirow[t]{2}{*}{ Comments } \\
\hline & Risk with 3D-CRT & Risk with IMRT & & & & \\
\hline $\begin{array}{l}\text { OS assessed with: } \\
\text { Kaplan-Meier } \\
\text { product limit }\end{array}$ & 40 per 100 & $\begin{array}{l}32 \text { per } 100 \\
(21 \text { to } 46)\end{array}$ & $\begin{array}{c}\mathrm{OR}=0.70 \\
(0.39-1.24)\end{array}$ & $\begin{array}{c}213 \\
\text { (3 RCTs) }\end{array}$ & $\begin{array}{c}\oplus \oplus \oplus \bigcirc \\
\text { MODERATE }^{\mathrm{a}, \mathrm{b}, \mathrm{c}}\end{array}$ & \\
\hline $\begin{array}{l}\text { LRC assessed with: } \\
\text { Kaplan-Meier } \\
\text { product limit }\end{array}$ & 17 per 100 & $\begin{array}{l}24 \text { per } 100 \\
(14 \text { to } 38)\end{array}$ & $\begin{array}{c}\mathrm{OR}=1.50 \\
(0.75-2.98)\end{array}$ & $\begin{array}{c}213 \\
(3 \mathrm{RCTs})\end{array}$ & $\begin{array}{l}\oplus \oplus \oplus \bigcirc \\
\text { MODERATE }\end{array}$ & \\
\hline $\begin{array}{l}\text { Acute xerostomia } \geq 2 \\
\text { assessed with: } \\
\text { Cumulative incidence }\end{array}$ & 76 per 100 & $\begin{array}{l}54 \text { per } 100 \\
(45 \text { to } 65)\end{array}$ & $\begin{array}{c}\mathrm{RR}=0.71 \\
(0.59-0.86)\end{array}$ & $\begin{array}{c}213 \\
\text { (3 RCTs) }\end{array}$ & $\begin{array}{c}\oplus \oplus \oplus \bigcirc \\
\text { MODERATE }^{\mathrm{a}, \mathrm{b}, \mathrm{c}}\end{array}$ & \\
\hline $\begin{array}{l}1 \text {-y xerostomia } \geq 2 \\
\text { assessed with: } \\
\text { Cumulative incidence }\end{array}$ & 59 per 100 & $\begin{array}{l}27 \text { per } 100 \\
(18 \text { to } 39)\end{array}$ & $\begin{array}{c}\mathrm{RR}=0.45 \\
(0.31-0.65)\end{array}$ & $\begin{array}{c}169 \\
\text { (3 RCTs) }\end{array}$ & $\begin{array}{c}\oplus \oplus \oplus \bigcirc \\
\text { MODERATE }^{\mathrm{a}, \mathrm{b}, \mathrm{c}}\end{array}$ & \\
\hline $\begin{array}{l}2 \text {-y xerostomia } \geq 2 \\
\text { assessed with: } \\
\text { Cumulative incidence }\end{array}$ & 55 per 100 & $\begin{array}{l}14 \text { per } 100 \\
(8 \text { to } 25)\end{array}$ & $\begin{array}{c}\mathrm{RR}=0.26 \\
(0.15-0.46)\end{array}$ & $\begin{array}{c}140 \\
\text { (3 RCTs) }\end{array}$ & $\begin{array}{c}\oplus \oplus \oplus \bigcirc \\
\text { MODERATE }^{\mathrm{a}, \mathrm{b}, \mathrm{c}}\end{array}$ & \\
\hline
\end{tabular}

*The risk in the intervention group (and its $95 \%$ confidence interval) is based on the assumed risk in the comparison group and the relative effect of the intervention (and its 95\% CI). CI: Confidence interval; LRC: loco-regional control; OR: odds ratio; OS: overall survival; RR: risk ratio. GRADE Working Group grades of evidence: High certainty: We are very confident that the true effect lies close to that of the estimate of the effect; Moderate certainty: We are moderately confident in the effect estimate: The true effect is likely to be close to the estimate of the effect, but there is a possibility that it is substantially different; Low certainty: Our confidence in the effect estimate is limited: The true effect may be substantially different from the estimate of the effect; Very low certainty: We have very little confidence in the effect estimate: The true effect is likely to be substantially different from the estimate of effect. aMissing outcome data balanced across groups; ${ }^{b}$ detection bias; ${ }^{c}$ may not be downgraded.

conclusive evidence in term of clinical outcomes. We hoped to draw attention to the paucity of good quality data on this topic and improve the quality of future research.

\section{Conclusion}

This meta-analysis confirmed the efficacy of IMRT to reduce moderate to severe xerostomia onset, but cannot determine meaningful survival advantages in HNSCC. Prospective randomized trials aimed to compare IMRT versus 3D-CRT in an adequate homogeneous HNSCC population, with survival and main RT-related toxicities endpoints are necessary to definitely confirm IMRT value.

\section{Conflicts of Interest}

All Authors declare that they have no conflicts of interest that may be relevant to the contents of this manuscript.

\section{Authors' Contributions}

FDF, NP, PP have made substantial contributions to the conception of the work, the acquisition and interpretation of data and have drafted the work; OB, VT and AP have substantively revised it. All Authors have approved the submitted version.

\section{References}

1 National Comprehensive Cancer Network (NCCN). Guidelines Head and Neck Cancers, Version 2.2018. Available at: http://www.nccn.org (Last accessed 21/11/2019)

2 De Felice F, Musio D, Terenzi V, Valentini V, Cassoni A, Tombolini M, De Vincentiis M and Tombolini V: Treatment improvement and better patient care: which is the most important one in oral cavity cancer? Radiat Oncol 9: 263, 2014. PMID: 25479896. DOI: 10.1186/s13014-014-0263-x

3 Marta GN, Silva V, de Andrade Carvalho H, de Arruda FF, Hanna SA, Gadia R, da Silva JL, Correa SF, Vita Abreu CE and Riera R: Intensity-modulated radiation therapy for head and neck cancer: systematic review and meta-analysis. Radiother Oncol 110(1): 915, 2014. PMID: 24332675. DOI: 10.1016/j.radonc.2013.11.010

4 Gupta T, Kannan S, Ghosh-Laskar S and Agarwal JP: Systematic review and meta-analyses of intensity-modulated radiation therapy versus conventional two-dimensional and/or or threedimensional radiotherapy in curative-intent management of head and neck squamous cell carcinoma. PLoS One 13(7): e0200137, 2018. PMID: 29979726. DOI: 10.1371/journal.pone.0200137

5 Nutting CM, Morden JP, Harrington KJ, Urbano TG, Bhide SA, Clark C, Miles EA, Miah AB, Newbold K, Tanay M, Adab F, Jefferies SJ, Scrase C, Yap BK, A'Hern RP, Sydenham MA, Emson $\mathrm{M}$, Hall E and PARSPORT trial management group: Parotidsparing intensity modulated versus conventional radiotherapy in head and neck cancer (PARSPORT): a phase 3 multicentre 
randomised controlled trial. Lancet Oncol 12(2): 127-136, 2011. PMID: 21236730. DOI: 10.1016/S1470-2045(10)70290-4

6 Rosenthal DI, Chambers MS, Fuller CD, Rebueno NC, Garcia J, Kies MS, Morrison WH, Ang KK and Garden AS: Beam path toxicities to non-target structures during intensity-modulated radiation therapy for head and neck cancer. Int $\mathrm{J}$ Radiat Oncol Biol Phys 72(3): 747-755, 2008. PMID: 18455324. DOI: 10.1016/j.ijrobp.2008.01.012

7 Rathod S, Gupta T, Ghosh-Laskar S, Murthy V, Budrukkar A and Agarwal J: Quality-of-life (QOL) outcomes in patients with head and neck squamous cell carcinoma (HNSCC) treated with intensity-modulated radiation therapy (IMRT) compared to threedimensional conformal radiotherapy (3D-CRT): evidence from a prospective randomized study. Oral Oncol 49(6): 634-642, 2013. PMID: 23562564. DOI: 10.1016/j.oraloncology.2013.02.013

8 Ghosh-Laskar S, Yathiraj PH, Dutta D, Rangarajan V, Purandare N, Gupta T, Budrukkar A, Murthy V, Kannan S and Agarwal JP: Prospective randomized controlled trial to compare 3dimensional conformal radiotherapy to intensity-modulated radiotherapy in head and neck squamous cell carcinoma: Longterm results. Head Neck 38: E1481-1487, 2016. PMID: 26561342. DOI: $10.1002 /$ hed.24263

9 Gupta T, Agarwal J, Jain S, Phurailatpam R, Kannan S, GhoshLaskar S, Murthy V, Budrukkar A, Dinshaw K, Prabhash K, Chaturvedi $\mathrm{P}$ and D'Cruz A: Three-dimensional conformal radiotherapy (3D-CRT) versus intensity modulated radiation therapy (IMRT) in squamous cell carcinoma of the head and neck: a randomized controlled trial. Radiother Oncol 104(3): 343-348, 2012. PMID: 22853852. DOI: 10.1016/j.radonc.2012.07.001

10 Moher D, Liberati A, Tetzlaff J, Altman DG and PRISMA Group: Preferred reporting items for systematic reviews and metaanalyses: the PRISMA statement. J Clin Epidemiol 62(10): 10061012, 2009. PMID: 25554246. DOI: 10.1186/2046-4053-4-1

11 Lefebvre C, Manheimer E and Glanville J: Chapter 6: Searching for studies. In: Higgins J, Green S (editors). Cochrane Handbook for Systematic Reviews of Interventions. Version 5.1.0 (updated March 2011). The Cochrane Collaboration, 2011. Available at: www.cochrane-handbook.org (Last accessed 21/11/2019)

12 Cox JD, Stetz J and Pajak TF: Toxicity criteria of the Radiation Therapy Oncology Group (RTOG) and the European Organization for Research and Treatment of Cancer (EORTC). Int J Radiat Oncol Biol Phys 31(5): 1341-1346, 1995. PMID: 7713792. DOI: 10.1016/0360-3016(95)00060-C

13 Guyatt G, Oxman AD, Akl EA, Kunz R, Vist G, Brozek J, Norris S, Falck-Ytter Y, Glasziou P, DeBeer H, Jaeschke R, Rind D, Meerpohl J, Dahm $P$ and Schünemann HJ: GRADE guidelines: 1. Introduction-GRADE evidence profiles and summary of findings tables. J Clin Epidemiol 64(4): 383-394, 2011. PMID: 21195583. DOI: 10.1016/j.jclinepi.2010.04.026

14 Cochrane. Available at: http://www.cochrane.org (Last accessed 21/11/2019)

15 Tierney JF, Stewart LA, Ghersi D, Burdett S and Sydes MR: Practical methods for incorporating summary time-to-event data into meta-analysis. Trials $8: 16,2007$. PMID: 17555582 . DOI: 10.1186/1745-6215-8-16

16 Higgins JPT, Thompson SG, Deeks JJ and Altman DG: Measuring inconsistency in meta-analyses. BMJ 327: 557-560, 2003. PMID: 12958120. DOI: 10.1136/bmj.327.7414.557

17 De Felice F, Thomas C, Barrington S, Pathmanathan A, Lei M and Urbano TG: Analysis of loco-regional failures in head and neck cancer after radical radiation therapy. Oral Oncol 51(11): 1051-1055, 2015. PMID: 26506048. DOI: 10.1016/j.oraloncology.2015.08.004

18 De Felice F, Musio D, Bulzonetti N, Maghella F and Tombolini $\mathrm{V}$ : Target volume delineation based on diffusion-weighted magnetic resonance imaging for locally advanced head and neck cancer. Anticancer Res 36(8): 4181-4185, 2016. PMID: 27466529.

19 De Felice F, Musio D, Terenzi V, Valentini V, Cassoni A, Tombolini M, De Vincentiis M and Tombolini V: Treatment improvement and better patient care: which is the most important one in oral cavity cancer? Radiat Oncol 9: 263, 2014. PMID: 25479896. DOI: 10.1186/s13014-014-0263-x

20 Murdoch-Kinch CA, Kim HM, Vineberg KA, Ship JA and Eisbruch A: Dose-effect relationships for the submandibular salivary glands and implications for their sparing by intensity modulated radiotherapy. Int J Radiat Oncol Biol Phys 72(2): $373-$ 382, 2008. PMID: 18337023. DOI: 10.1016/j.jjrobp.2007.12.033

21 De Felice F, Musio D and Tombolini V: Osteoradionecrosis and intensity modulated radiation therapy: An overview. Crit Rev Oncol Hematol 107: 39-43, 2016. PMID: 27823650. DOI: 10.1016/j.critrevonc.2016.08.017

22 De Felice F, Thomas C, Patel V, Connor S, Michaelidou A, Sproat C, Kwok J, Burke M, Reilly D, McGurk M, Simo R, Lyons A, Oakley R, Jeannon JP, Lei $M$ and Urbano TG: Osteoradionecrosis following treatment for head and neck cancer and the effect of radiotherapy dosimetry: the Guy's and St Thomas' Head and Neck Cancer Unit experience. Oral Surg Oral Med Oral Pathol Oral Radiol 122(1): 28-34, 2016. PMID: 27039003. DOI: 10.1016/j.0ooo.2016.01.007

23 De Felice F, de Vincentiis M, Luzzi V, Magliulo G, Tombolini M, Ruoppolo $\mathrm{G}$ and Polimeni A: Late radiation-associated dysphagia in head and neck cancer patients: evidence, research and management. Oral Oncol 77: 125-130, 2018. PMID: 29362118. DOI: 10.1016/j.oraloncology.2017.12.021

24 Gilbert A, Ziegler L, Martland M, Davidson S, Efficace F, SebagMontefiore D and Velikova G: Systematic review of radiation therapy toxicity reporting in randomized controlled trials of rectal cancer: A comparison of patient-reported outcomes and clinician toxicity reporting. Int J Radiat Oncol Biol Phys 92(3): 555-567, 2015. PMID: 26068490. DOI: 10.1016/j.ijrobp.2015.02.021

25 Balshem H, Stevens A, Ansari M, Norris S, Kansagara D, Shamliyan T, Chou R, Chung M, Moher D and Dickersin K: Finding grey literature evidence and assessing for outcome and analysis reporting biases when comparing medical interventions: AHRQ and the effective health care program. Agency for healthcare research and Quality, AHRQ methods for effective health care, 2013. PMID: 24404628.

26 Lydiatt WM, Patel SG, O'Sullivan B, Brandwein MS, Ridge JA, Migliacci JC, Loomis AM and Shah JP: Head and Neck cancersmajor changes in the American Joint Committee on cancer eighth edition cancer staging manual. CA Cancer J Clin 67(2): 122-137, 2017. PMID: 28128848. DOI: 10.3322/caac.21389

Received November 16, 2019

Revised November 21, 2019

Accepted November 26, 2019 